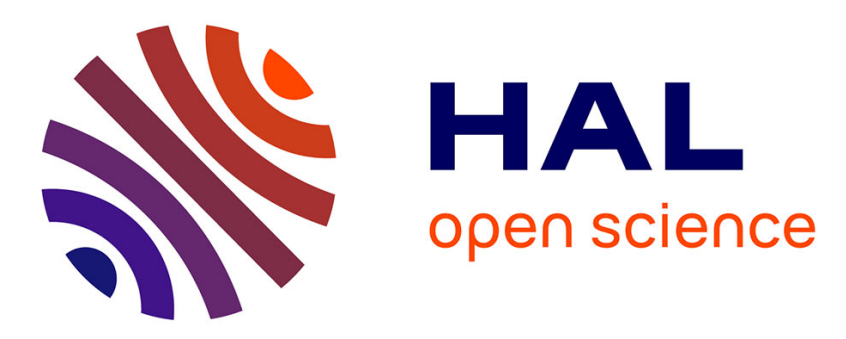

\title{
Organic photoredox catalysis for the oxidation of silicates: applications in radical synthesis and dual catalysis
}

Christophe Lévêque, Ludwig Chenneberg, Vincent Corcé, Cyril Ollivier, Louis Fensterbank

\section{To cite this version:}

Christophe Lévêque, Ludwig Chenneberg, Vincent Corcé, Cyril Ollivier, Louis Fensterbank. Organic photoredox catalysis for the oxidation of silicates: applications in radical synthesis and dual catalysis. Chemical Communications, 2016, 52, pp.9877-9880 10.1039/C6CC04636C . hal-01346464

\section{HAL Id: hal-01346464 https://hal.sorbonne-universite.fr/hal-01346464}

Submitted on 19 Jul 2016

HAL is a multi-disciplinary open access archive for the deposit and dissemination of scientific research documents, whether they are published or not. The documents may come from teaching and research institutions in France or abroad, or from public or private research centers.
L'archive ouverte pluridisciplinaire HAL, est destinée au dépôt et à la diffusion de documents scientifiques de niveau recherche, publiés ou non, émanant des établissements d'enseignement et de recherche français ou étrangers, des laboratoires publics ou privés. 


\section{Organic Photoredox Catalysis for the Oxidation of Silicates: Applications in Radical Synthesis and Dual Catalysis}

Received 00th January 20xx, Accepted 00th January 20xx DOI: $10.1039 / \times 0 \times x 00000 x$

www.rsc.org/

Metal free photooxidation of alkyl bis(catecholato)silicates with the organic dye, 1,2,3,5-tetrakis(carbazol-9-yl)-4,6-dicyanobenzene (4CzIPN), allows the smooth formation of alkyl radicals. The latter can be efficiently engaged either with radical acceptors to provide homolytic addition products or in photoredox/nickel dual catalysis reactions to obtain cross-coupling products.

Visible-light photoredox catalysis $^{1}$ has emerged as a powerful strategy to generate radical species replacing more and more tin-mediated or stoichiometric redox methodologies. ${ }^{2}$ Many opportunities are now available to access all kinds of C-centered radicals, based whether on photooxidative or photoreductive processes. ${ }^{1}$ In this context, we and subsequently the group of Molander showed recently that the photooxidation of alkyl bis(catecholato)silicates ${ }^{3}$ is a very convenient source of alkyl radicals. This process constitutes a significant advance with advantageous features compared to the photooxidation of carboxylates ${ }^{4}$ and trifluoroborates, ${ }^{5}$ which is limited to stabilized alkyl radicals ${ }^{4,5}$ (allylic, benzylic and $\alpha$-heterosubstituted radicals). In contrast, given their lower oxidation potential, alkyl bis(catecholato)silicates offer more scope. So far, their effective oxidation has only been described with photocatalysts based on expensive metals ${ }^{3}$ (Ir, Ru). Alternatively, we have sought to explore more sustainable processes using easily accessible organic dyes. ${ }^{6}$ In a preliminary study, ${ }^{3 b}$ it was found that only the highly oxidizing Fukuzumi acridinium photocatalyst ${ }^{6 a}$ showed some activity, limited to allylic and benzylic silicates. In 2012, Adachi et al. described a family of carbazoyl dicyanobenzenes as lightharvesters for organic light-emitting diodes. ${ }^{7}$ Among them, 1,2,3,5-tetrakis-(carbazol-yl)-4,6-dicyanobenzene (4CzIPN) displayed promising features for photoredox catalysis: a high photoluminescence quantum yield $(94.6 \%)$ and a long life-time at the excited state $(5.1 \mu \mathrm{s})$. Recently, Zhang et al. reported the redox properties of this photosensitizer ${ }^{8}$ and the given value for the oxidative potential of the photoexcited 4CzIPN $\left(\mathrm{E}_{1 / 2}{ }^{*}\left(4 \mathrm{Cz} \mathrm{IPN} /[4 \mathrm{CZIPN}]^{-}\right)=+1.35 \mathrm{~V}\right.$ vs SCE) augured well for a

\footnotetext{
a. Institut Parisien de Chimie Moléculaire, UMR CNRS 8232, Sorbonne Universités UPMC Univ Paris 06. 4 Place Jussieu, CC 229, F-75252 Paris Cedex 05, France Electronic Supplementary Information (ESI) available: [details of any supplementary information available should he included herel. See DOI: $10.1039 / \mathrm{x} 0 \mathrm{xx} \cap 0000 \mathrm{x}$
}

possible photooxidation of alkyl bis(catecholato)silicates $\left(E_{1 / 2}(\mathrm{Ox} / \mathrm{red})=+0.3\right.$ to $+0.9 \mathrm{~V}$ vs $\left.\mathrm{SCE}\right) .^{3 \mathrm{a}}$ We thus decided to assess this reactivity with a series of alkylsilicates and the cheapest photocatalyst 4CzIPN $(\$ 0.06 / \mathrm{mmol}$ for carbazole, $\$ 2.2 / \mathrm{mmol}$ for tetrafluoroisophthalonitrile ${ }^{9}$ ) in both radical synthesis and dual catalysis.

The ability of 4CzIPN to oxidize benzylsilicate 1a in spin trapping experiments with TEMPO, acting both as radical trap and presumably also as sacrificial electron acceptor, was first explored (Table 1). ${ }^{3,5}$ The reaction was performed in a $0.1 \mathrm{M}$ DMF solution under blue LEDS irradiation $(477 \mathrm{~nm})$ with 1 a

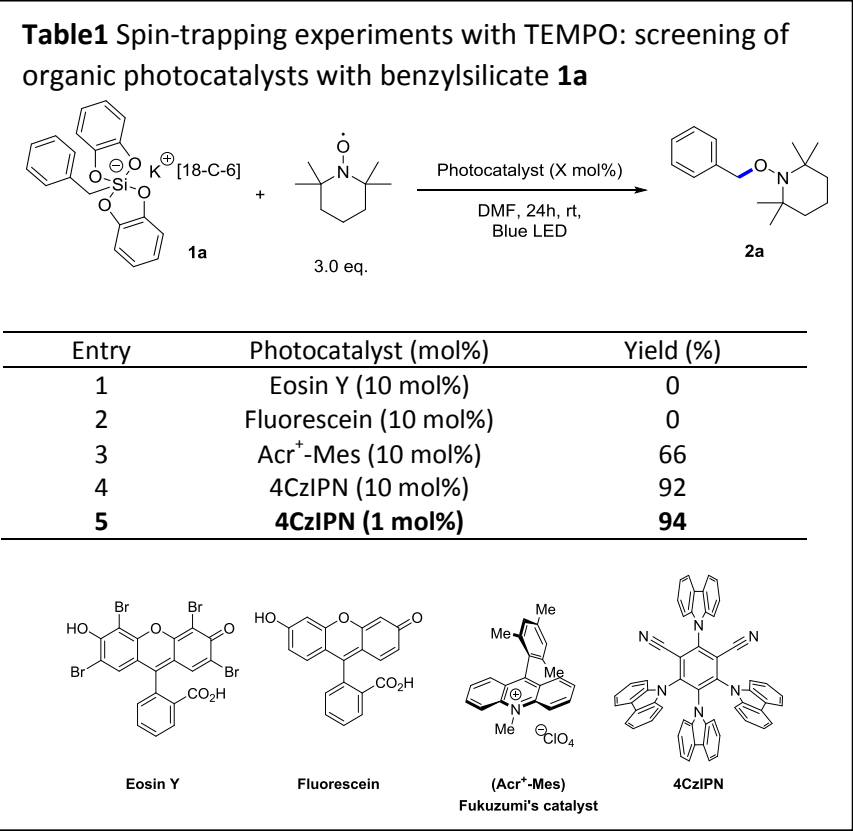

(0.3 mmol), TEMPO (0.9 mmol) and the organic dye (10 mol\%). Only Fukuzumi acridinium ( $\mathrm{Acr}^{+}-\mathrm{Mes}$ ) and 4CzIPN gave the expected TEMPO adduct $\mathbf{2 a}$ in $66 \%$ and $92 \%$ yields respectively. ${ }^{3 b}$ Furthermore, the catalytic loading in 4 CzIPN could be diminished down to $1 \mathrm{~mol} \%$ without any erosion of the yield (entry 5). These preliminary results excited our interested in further uses of 4CzIPN. 
Therefore, we engaged various alkylsilicates 1 in a series of diagnostic radical addition experiments (Table 2 ). Using first allylsulfone $\mathbf{3 a}$, we surmised the following catalytic cycle. ${ }^{3 a}$ Photoexcited 4 CzIPN ${ }^{*}$ would oxidize the alkylsilicate derivative via a SET mechanism leading to the [4CzIPN] ${ }^{-}$anion and a hypervalent 5-coordinate silicon radical. Upon homolytic fragmentation of the $\mathrm{C}$-Si bond, the generated $\mathrm{C}$-centered radical would add to allylsulfone $\mathbf{3 a}$, providing a $\beta$-sulfonyl radical which after fragmentation liberates the allylation adduct and a tosyl radical. A SET step would regenerate the photocatalyst and give a sulfinate anion.

Based on this catalytic cycle, allylation adducts were obtained in excellent yields for stabilized radicals (4ab, 4ac) and secondary radical (4ad), to moderate yields for primary radicals (4ae, 4af, 4ag) (Table 2). Interestingly, silicate $\mathbf{1 f}$ furnished the carbon allylation adduct, without fragmentation of the $\mathrm{Ph}_{2} \mathrm{PO}$ radical. ${ }^{10}$ Encouraged by these results, we engaged cyclohexylsilicate $\mathbf{1 d}$ in various radical reactions like alkynylation, ${ }^{11}$ vinylation $^{11}$ and Giese-type reaction leading efficiently to products $\mathbf{4} \mathbf{b d}, \mathbf{4} \mathbf{c d}$ and $\mathbf{4 d d}$. It should be noted that similar additions can be performed by photocatalytic reduction of alkyl halides or related precursors but they generally rely on activated substrates or very special functions. $^{12}$

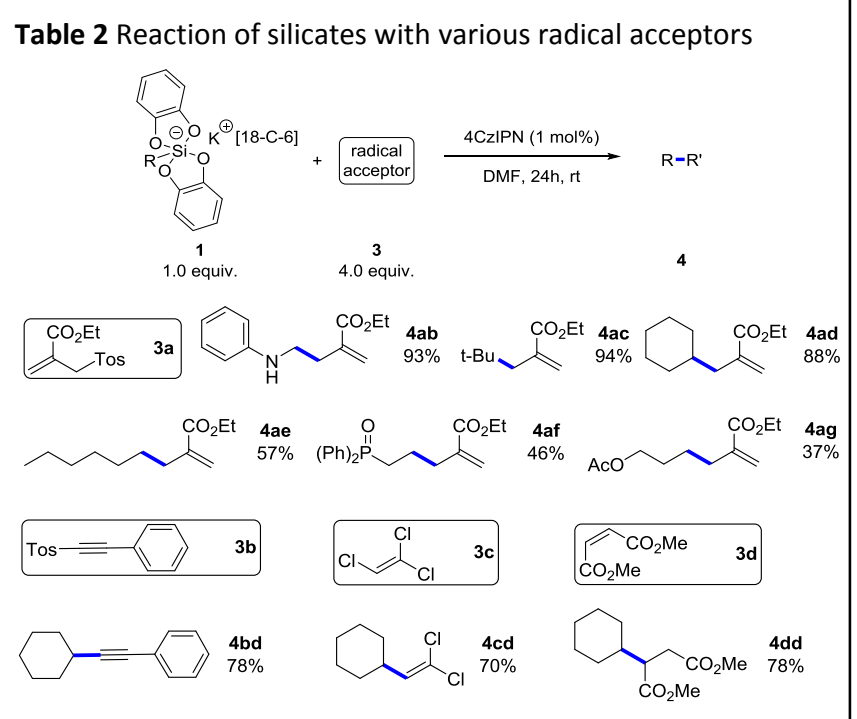

Zhang et al. also reported ${ }^{8}$ the first examples of the use of 4 CzIPN as photocatalyst in photoredox/nickel dual-catalyzed ${ }^{13}$ cross-coupling reactions of aminocarboxylates and benzyltrifluoroborates with arylbromides. In the same vein, we planned to extend this mixed photoorganic/metallic dualcatalysis to alkylsilicates. ${ }^{14}$ Thus, a mixture of 4 '-bromoacetophenone $\mathbf{5 a}$ with acetoxypropylsilicate $\mathbf{1 g}$ in the presence of 4CzIPN (2 mol\%), $\mathrm{NiCl}_{2}$.dme (5 mol \%) and 4,4'-di-tert-butylLED) for 24 hours at rt. In these conditions, an excellent $81 \%$ yield of coupling product $\mathbf{6 a g}$ was observed (Table 3 ). Furthermore, we were able to reduce the catalytic loading in photocatalyst and nickel to $1 \mathrm{~mol} \%$ and $2 \mathrm{~mol} \%$ respectively, giving 6 ag in $83 \%$ isolated yield (entry 3 ). However, decreasing the amount of alkylsilicate drastically affected the yield of the reaction (entry 5). Interestingly, no product was observed
Table 3 Screening of reaction conditions for photoredox/nickel

dual-catalyzed cross-coupling

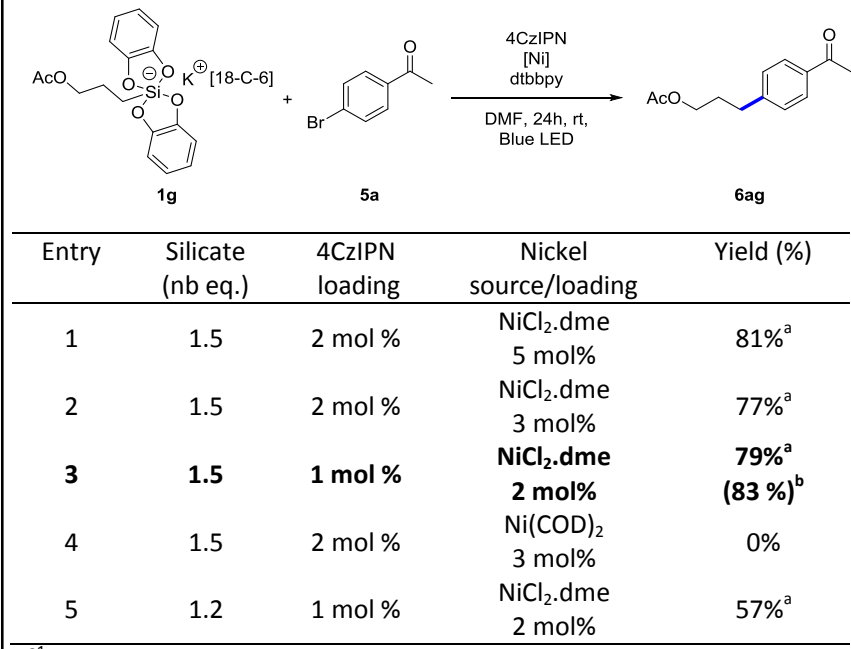

${ }^{\mathrm{a} 1 \mathrm{H}}$ NMR yield with butadiene sulfone as internal standard , $0.3 \mathrm{mmol}$ scale. ${ }^{\mathrm{b}}$ Isolated yield.

when a $\mathrm{Ni}(0)\left(\mathrm{Ni}(\mathrm{COD})_{2}\right)$ precatalyst was tested (entry 4). This finding suggests a catalytic cycle starting from a Ni(II) species as previously described by Johannes et al. ${ }^{15}$

The scope of this reaction was investigated focusing initially on the influence of aryl ring substitution (Table 4). A better yield was observed with an electron neutral $(6 \mathrm{cg})$ or an

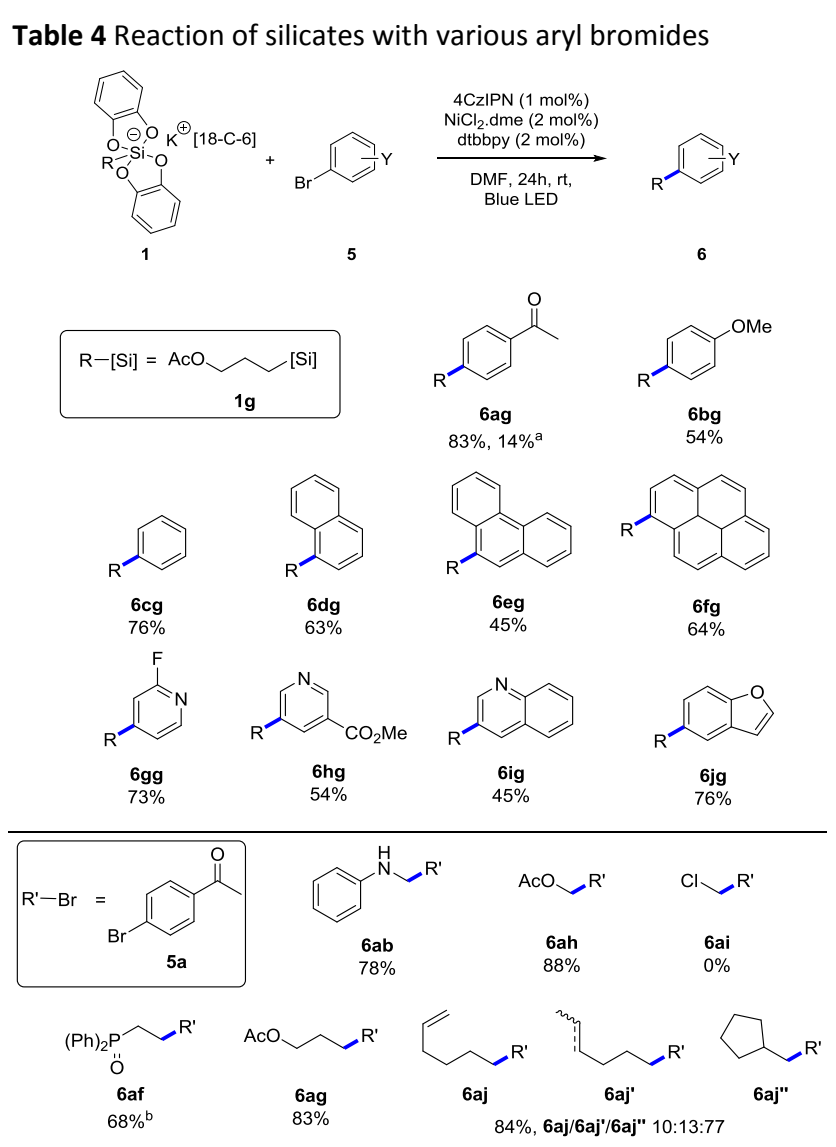

a Experiment realized with 4'-chloroacetophenone. ${ }^{b}$ Yield determined in a mixture with ethyldiphenylphosphine oxide ( $15 \%$ of byproduct). 
electron withdrawing group (6ag) than with a methoxy substituted substrate (6bg). Polyaromatic substrates also gave the expected products (6/g-6fg) in good to moderate yields. Moreover, when 4'-chloroacetophenone was engaged the yield of the reaction dropped dramatically (from $83 \%$ to $14 \%$ of 6ag). This highlights the importance of the oxidative addition step, in accordance with the postulated mechanism. ${ }^{13,14}$ Heteroaryl bromides can also act as electrophilic partners. Pyridines (6gg and 6hg), quinoline (6ig) or benzofuran derivatives (6jg) provided coupling products in moderate to good yields. In addition, the compatibility of several types of alkylsilicates was explored with 4'-bromoacetophenone. An assortment of key functions such as amine (6ab), ester (6ah and $\mathbf{6 a g}$ ) or phosphine oxide (6af) was well tolerated in the reaction conditions. In all cases, products were obtained in good to fair yields regardless of the stability of the generated $C$ centered radical. Concerning silicate $1 \mathbf{f}$ as before, no product derived the generation of a P-centered radical was observed. ${ }^{10,16}$ Not surprisingly, chloromethylsilicate $\mathbf{1 h}$ did not give the desired product (6ha). Finally, the reactivity of hex-1enylsilicate $\mathbf{1} \mathbf{j}$ was examined with 4'-bromoacetophenone and resulted in a mixture of products 6ja, 6j'a and 6j"a in a $10 / 13 / 77$ ratio and $82 \%$ overall yield. Here, the intermediate 5 hexenyl radical would directly react to provide product $\mathbf{6 j a}$ and 6j'a resulting from post-isomerization of $\mathbf{6 j a} .{ }^{17}$ Interestingly, the formation of the major product 6j"a implies a 5-exo-trig cyclization step prior to the coupling process.

In order to illustrate the versatility of 4CzIPN as photocatalyst for this type of dual catalysis, a scale-up experiment was accomplished using acetoxypropylsilicate $\mathbf{1 g}$ and 4 '-bromoacetophenone. The reaction conditions were the same as previously except the reaction time. Indeed, after $24 \mathrm{~h}$ of reaction, only $63 \%$ yield of 6 ag was obtained, which could be further improved to $76 \%$ yield by increasing the reaction time to $48 \mathrm{~h}$ (Table 5).

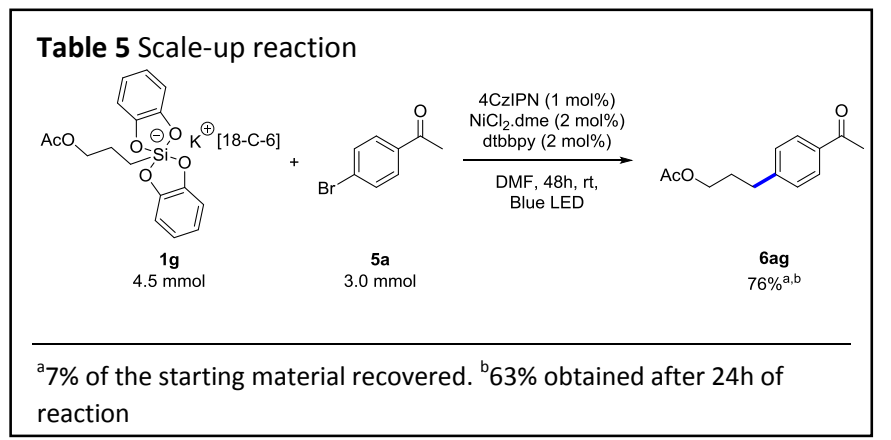

Finally, a series of alkenyl bromides was treated under the dual catalysis conditions (Table 6). Unactivated alkenyl bromides were converted to their corresponding products in moderate yields (8ag-8cg). However, activated alkenyl bromides such as styryl bromide, styryl chloride, and $\beta$-gemdichlorostyrene gave fair to good yields of coupling products, respectively $\mathbf{8 d g}$ and $\mathbf{8 d} \mathbf{d}$, $\mathbf{8} \mathbf{e g}$ and $\mathbf{8 f g}$.

Concerning $\beta$-bromostyrene $\mathbf{6} \mathbf{d} / \mathbf{6} \mathbf{d}$ ', complete retention of the double bond geometry was observed when using each pure isomer. Same result was observed starting from the commercial mixture of both isomers (ratio Z/E: 15/85). It was

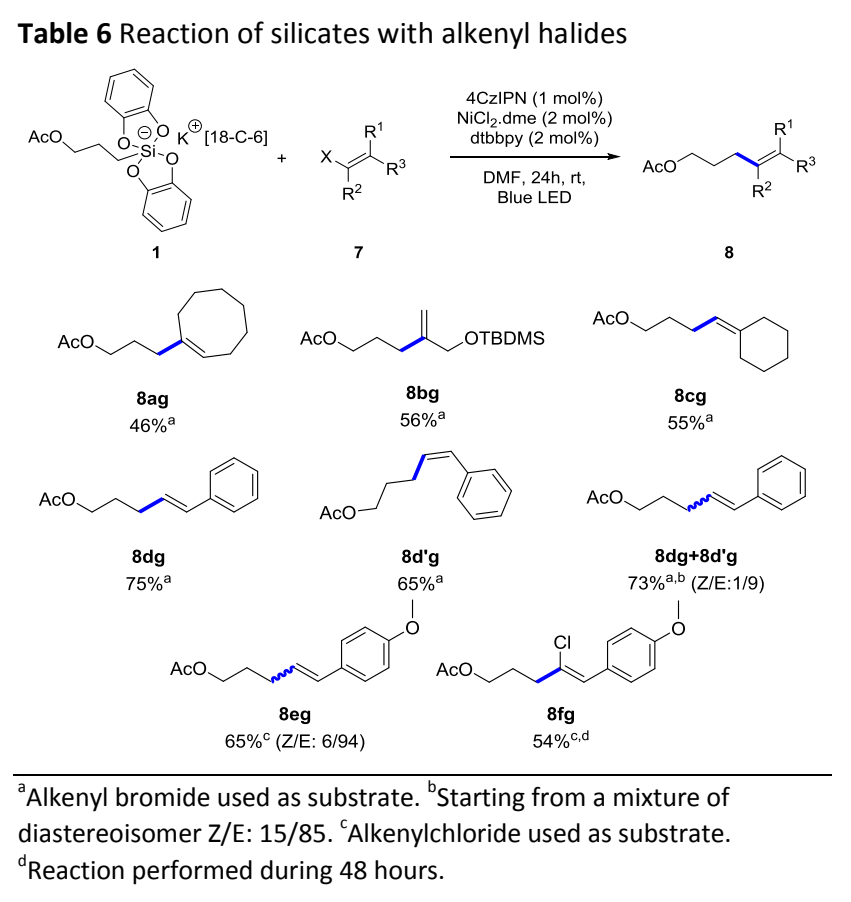

interesting to compare this finding with the metallic photocatalysts $\mathrm{Ru}(\mathrm{bpy})_{3}\left(\mathrm{PF}_{6}\right)_{2}$ and $\left[\operatorname{Ir}\left(\mathrm{dF}\left(\mathrm{CF}_{3}\right) \mathrm{ppy}\right)_{2}(\mathrm{bpy})\right]\left(\mathrm{PF}_{6}\right)$ (Table 7). Previously reported conditions ${ }^{3 c, 14 b}$ led to the expected products $\mathbf{8 d g , 8 d ' g}$ in $75 \%$ (Z/E: 15/85) yield with ruthenium and $90 \%$ (Z/E: 33/67) with iridium (Table 7, entries 2 and 3 ). We also verified that the reaction does not follow a pure radical vinylation mechanism involving an addition- $\beta$ elimination tandem. However, only traces of products $(\mathbf{8} \mathbf{f d}$ and $\mathbf{8} \mathbf{f d}$ ') were obtained when running the reaction in the absence

Table 7 Comparison of experimental conditions for photoredox/nickel dual-catalysis with $\beta$-bromostyrene

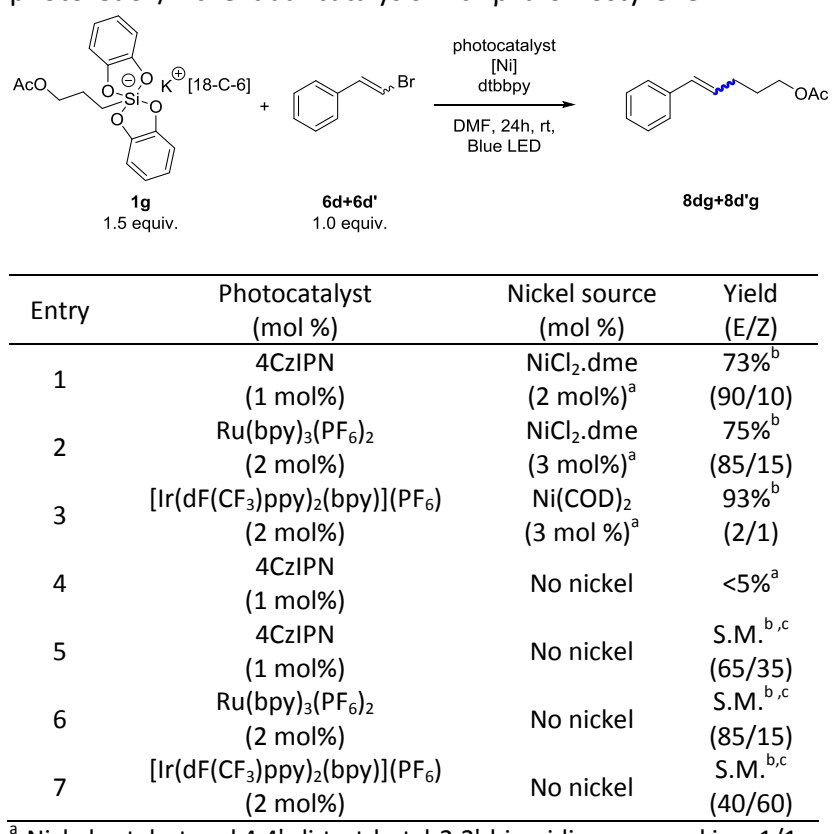

${ }^{a}$ Nickel catalyst and 4,4'-di-tert-butyl-2,2'-bipyridine engaged in a 1/1 ratio. 'Starting from a commercial mixture of diastereoisomer E/Z: 85/15. ' Experiment performed without silicate. 
of nickel salt and dtbbpy ligand (entry 4) which precluded the exclusive radical pathway. Isomerization of $\beta$-bromostyrene in the presence of a photosensitizer has been already reported. ${ }^{18}$ Control experiments were realized in the absence of nickel catalyst and silicate and showed that the bromide slightly isomerized in the presence of 4CZIPN (E/Z 65:35) compared to an $E / Z$ ratio of $40: 60$ with the iridium complex (entries 5 and 7). In this case, a heavy atom effect, brought by the bromide atom would easily give access to the triplet state ${ }^{19}$ of the styryl derivatives which promotes the isomerization. In contrast, no isomerization was observed with the ruthenium complex (entry 6) probably due to the lower energy state of the photoexcited $\left[\mathrm{Ru}(\mathrm{bpy})_{3}\right]^{2+*}$. Thus, even if this organic-dye can act as a photosensitizer of $\beta$-bromostyrene, the oxidation process of silicates is faster than the photoisomerization of the substrate. Therefore, stereoselective alkenyl-alkyl crosscoupling are also workable.

In conclusion, all these results demonstrate that 4CzIPN is as efficient as metal based photocatalysts for the photooxidation of alkyl bis(catecholato)silicates. The generated radicals can be engaged efficiently with radical acceptors and also in organic photoredox/nickel dual-catalysed processes with (hetero)aryl halides and alkenyl halides affording in that case alkene derivatives with high stereoselectivity. Requiring only a low catalytic loading (1 mol\%), 4CzIPN opens very exciting perspectives for more sustainable photoredox catalysis.

We thank CNRS, UPMC, IUF, MSER (ASN PhD grant to $\mathrm{CL}$ ), LABEX MiChem (ANR-11-IDEX-0004-02), La Région Martinique (PhD grant to LC), ANR NHCX (11-BS07-008, postdoc grant to VC) and COST Action CM1201. Omar Khaled is also acknowledged for HRMS.

\section{Notes and references}

1 (a) J. W. Tucker and C. R. J. Stephenson, J. Org. Chem., 2012, 77, 1617; (b) C. K. Prier, D. A. Rankic and D. W. C. MacMillan, Chem. Rev., 2013, 113, 5322; (c) B. König, Ed.; Chemical Photocatalysis; Walter de Gruyter GmbH \& Co. KG: Berlin, 2013; (d) D. M. Schultz and T. P. Yoon, Science, 2014, 343, 1239176-1; (e) D. Ravelli, S. Protti and M. Fagnoni, Chem. Rev., 2016, 116, 5322 DOI: 10.1021/acs.chemrev.5b00662.

2 (a) P. Renaud and M. P. Sibi, Radicals in Organic Synthesis, Wiley-VCH, Weinheim, 2001; (b) D. P. Curran, N. A. Porter and B. Giese, Stereochemistry of Radical Reactions, Wiley-VCH, Weinheim,1996.

3 (a) V. Corcé, L.-M. Chamoreau, E. Derat, J.-P. Goddard, C. Ollivier and L. Fensterbank, Angew. Chem. Int. Ed., 2015, 54, 11414; (b) L. Chenneberg, C. Lévêque, V. Corcé, A. Baralle, J.P. Goddard, C. Ollivier and L. Fensterbank, Synlett, 2016, 27, 731; (c) M. Jouffroy, D. N. Primer and G. A. Molander, J. Am. Chem. Soc., 2016, 138, 475.

4 (a) A. Noble and D. W. C. MacMillan, J. Am. Chem. Soc., 2014, 136, 11602; (b) C. K. Prier and D. W. C. MacMillan, Chem. Sci., 2014, 5, 4173; (c) C. C. Nawrat, C. R. Jamison, Y. Slutskyy, D. W. C. MacMillan and L. E. Overman, J. Am. Chem. Soc., 2015, 137, 11270.

5 (a) Y. Yasu, T. Koike and M. Akita, Adv. Synth. Catal., 2012, 354, 3414; (b) K. Miyazawa, Y. Yasu, T. Koike and M. Akita,
Chem. Commun., 2013, 49, 7249; (c) Y. Li, K. Miyazawa, T. Koike and M. Akita, Org. Chem. Front., 2015, 2, 319.

6 (a) S. Fukuzumi, and K. Ohkubo, Org. Biomol. Chem. 2014, 12, 6059; (b) D. A. Nicewicz and T. M. Nguyen, ACS Catal. 2014, 4, 355; (c) Ravelli, D.; Fagnoni, M. ChemCatChem 2012, 4, 169.

7 H. Uoyama, K. Goushi, K. Shizu, H. Nomura and C. Adachi, Nature, 2012, 492, 234.

8 J. Luo and J. Zhang, ACS Catal., 2016, 6, 873.

9 In comparison: $\$ 1.3 \mathrm{k} / \mathrm{mmol}$ for $\left[\operatorname{Ir}\left(\mathrm{dF}\left(\mathrm{CF}_{3}\right) \text { ppy }\right)_{2}(\mathrm{bpy})\right]\left(\mathrm{PF}_{6}\right)$, $\$ 110 / \mathrm{mmol}$ for $\mathrm{Ru}(\mathrm{bpy})_{3}\left(\mathrm{PF}_{6}\right)_{2}$. Prices available at http://www.Sigmaaldrich.com.

10 (a) D. Leca, L. Fensterbank, E. Lacôte and M. Malacria, Angew. Chem. Int. Ed., 2004, 43, 4220; (b) G. Ouvry, B. Quiclet-Sire and S. Z. Zard, Angew. Chem. Int. Ed., 2006, 45, 5002.

11 A.-P. Schaffner, V. Darmency and P. Renaud, Angew. Chem. Int. Ed., 2006, 45, 5847.

12 (a) K. Okada, K. Okamoto, N. Morita, K. Okubo and M. Oda, J. Am. Chem. Soc., 1991, 113, 940; (b) R. S. Andrews, J. J. Becker and M. R. Gagne, Angew. Chem. Int. Ed., 2010, 49, 7274; (c) M. J. Schnermann and L. E. Overman, Angew. Chem. Int. Ed., 2012, 51, 9576; (d) Y. Sun, R. Li, W. Zhang and A. Li, Angew. Chem. Int. Ed., 2013, 52, 9201; (e) S. Zhou, D. Zhang, Y. Sun, R. Li, W. Zhang and A. Li, Adv. Synth. Catal., 2014, 356, 2867; (f) S. Donck, A. Baroudi, L. Fensterbank, J.-P. Goddard and C. Ollivier, Adv. Synth. Catal., 2014, 355, 1477; (g) A. Baralle, L. Fensterbank, , J.-P. Goddard and C. Ollivier, Chem. Eur. J., 2013, 19, 10809.

13 (a) Z. Zuo, D. T. Ahneman, L. Chu, J. A. Terrett, A. G. Doyle and D. W. C. MacMillan, Science, 2014, 345, 437. (b) J. C. Tellis, D. N. Primer and G. A. Molander, Science, 2014, 345, 433. (c) S. Z. Tasker, T. F. Jamison J. Am. Chem. Soc. 2015, 137, 9531. For reviews on dual catalysis see: (d) M. N. Hopkinson, B. Sahoo, J.-L. Li, F. Glorius, Chem. Eur. J., 2014, 20, 3874; (e) C. Vila, ChemCatChem, 2015, 7, 1790; (f) J. J. Murphy and P. Melchiorre, Nature, 2015, 524, 297; (g) Y.-Y. Gui, L. Sun, Z.-P. Lu and D.-G. Yu, Org. Chem. Front., 2016, 3, 522; (h) K. L. Skubi, T. R. Blum and T. P. Yoon, Chem. Rev., 2016, 116, DOI: 10.1021/acs.chemrev.6b00018; (i) M. D. Levin, S. Kim, F. D. Toste, ACS Cent. Sci. 2016 DOI: 10.1021/acscentsci.6b00090.

14 See refs. 3a and 3c. See also: (a) C. Lévêque, L. Chenneberg, V. Corcé, J.-P. Goddard, C. Ollivier and L. Fensterbank, Org. Chem. Front., 2016, 3, 462; (b) N. R. Patel, C. B. Kelly, M. Jouffroy and G. A. Molander, Org. Lett., 2016, 18, 764; (c) M. Jouffroy, C B Kelly and G. A. Molander, Org. Lett., 2016, 18, 876; (d) M. Jouffroy, G. H. M. Davies and G. A. Molander, Org. Lett., 2016, 18, 1606.

15 M. S. Oderinde, M. Frenette, D. W. Robbins, B. Aquila and J. W. Johannes, J. Am. Chem. Soc., 2016, 138, 1760.

16 (a) Y. He, H. Wuab and F. D. Toste, Chem. Sci., 2015, 6, 1194. (b) J. Xuan, T. T. Zeng, J. R. Chen, L. Q. Lu and W. J. Xiao, Chem. Eur. J., 2015, 21, 4962.

17 (a) R. G. Miller, P. A. Pinke, R. D. Stauffer, H. J. Golden and D. J. Baker, J. Am. Chem. Soc., 1974, 96, 4211; (b) F. Weber, A. Schmidt, P. Röse, M. Fischer, O. Burghaus and Gerhard Hilt, Org. Lett., 2015, 17, 2952.

18 (a) Y.-P. Zhao, L.-Y. Yang and R. S. H. Liu, Green Chem., 2009, 11, 837; (b) K. Singh, S. J. Staig and J. D. Weaver, J. Am. Chem. Soc., 2014, 136, 5275.

19 For a review on molecular photochemistry, see: N. J. Turro, V. Ramamurthy and J. C. Scaiano, Modern Molecular Photochemistry, University Science Books, Sausalito CA, 1991. 